\title{
Towards a new welfare state: the social sustainability principle and health care strategies
}

\author{
Jorge Garcés $^{\mathrm{a}, *}$, Francisco Ródenas ${ }^{\mathrm{b}}$, Vicente Sanjosé ${ }^{\mathrm{c}}$ \\ a Department of Ideology and Social Policy, University of Valencia, Valencia, Spain \\ ${ }^{\mathrm{b}}$ Department of Social Welfare Systems, University of Valencia, Valencia, Spain \\ ${ }^{\mathrm{c}}$ Department of Scientific Education, University of Valencia, Valencia, Spain \\ Received 2 February 2002; accepted 4 October 2002
}

\begin{abstract}
In this paper we propose a social and health care model that offers alternatives to three problems arising in converging European welfare states, particularly in the southern nations: the rise in demand for services and features linked to the ageing process, the increase in dependency and the crisis of informal support. Development of the principles of social sustainability implies re-formulation of the regulatory, care, economic, administrative, cultural, and axiological framework enabling a response to the needs of long term care without compromising the welfare of future generations. Together with this principle, quality of life elevated to a subjective right directs attention towards the sphere closest to citizens, eliminating all barriers, which hamper exercise of this right. All of the above produces economic and social costs which must be accepted from a viewpoint of social co-responsibility, which brings with it the supply of welfare individually, without detriment to the exercise of state responsibility in guaranteeing a social protection system of a universal nature.
\end{abstract}

(C) 2003 Elsevier Science Ireland Ltd. All rights reserved.

Keywords: European welfare states; Axiological framework; Social sustainability; Health care strategies

\section{European convergence: the same problem with different solutions?}

For 40 years these countries have developed ways of putting into action the ideas on state

\footnotetext{
* Corresponding author. Present address: Departamento Trabajo Social y Servicios Sociales, University of Valencia, Campus Tarongers - Edificio Departamental Occidental Avda. dels. Tarongers, s/n-46022 Valencia, Spain. Tel.: +96-382-8184; fax: +96-382-81-88.

E-mail address: jordi.garces@uv.es (J. Garcés).
}

welfare conceived by socialist and social democratic theorists, liberal thinkers like Belveridge and charismatic politicians like Bismarck, in such a manner that at least four different models have been defined which cover virtually all the European states: (a) The Nordic model to which Sweden, Norway, Denmark, and Finland would belong; (b) The Bismarckian model, represented by France, Germany, Belgium, Luxembourg and Austria; (c) The Belveridge model followed by UK, the Netherlands and Eire; (d) The Mediterranean model, represented by Portugal, Spain, 
Italy and Greece. These models correspond, though not exclusively, to their geopolitical distribution respectively in the northern, central continental, western and southern areas of Europe, and their geographic distribution is also often used as a criterion for grouping them.

In practice, decisions made regarding the roles of the state, the market and the family in welfare definition, responsibility, provision and finance on one hand, and the cultural tradition of each society on the other are what distinguish the different models from each other. For example, Ascoli and Pavolini [1] place the four European models inside another four quadrants defined along two axes: the state culture of solidarity/subsidiarily; and involvement/noninvolvement of the service sector in state policy making (Fig. 1).

Nowadays it is possible to distinguish between the different countries through many welfare indicators, such as:

a) Spending on social protection, with current levels of more than $33 \%$ of GDP in Nordic countries, and lower than $25 \%$ in southern states;

b) State tax collection, higher than $50 \%$ of GDP in Nordic countries, around 35\% in the southern states, UK and Eire, and roughly $45 \%$ among the rest;

c) Female employment rate, near $90 \%$ in Scandinavia but under $60 \%$ in southern Europe

d) Standardised spending on active measures in the labour market, in which the southern countries are running at one third the rate of Scandinavia and half the rate of the rest of Europe;

e) Intensity of welfare services provided by family and relatives, between 2 and 10 times greater in the Mediterranean countries than in the rest.

These indicators distinguish between the welfare relations in different countries as well as the relative importance of one or another institution in welfare provision.

Nonetheless, if we take a diachronic viewpoint to analyse changes in these variables over time, we find evolutionary patterns which in many cases tend towards convergence. In fact, the firm decision to build the European Union over the final years of the 20th century and the globalisation of the economy at the outset of the 21st century for the individual states imposes convergence and unification in political, social, and legislative criteria. We can even make out a tendency to use the same moral discourse on which the justification for adopting these criteria is based.

Among the variety of indicators supporting the idea of convergence, we can remark, for example, the evolution over the last 20 years in social protection spending among European countries ([2]). In 1980, Portugal, Italy, Spain and Greece were starting from substantially lower social protection levels than the other European countries. At that time, Portugal was budgeting 1/6 of the European average, representing $1 / 10$ of the

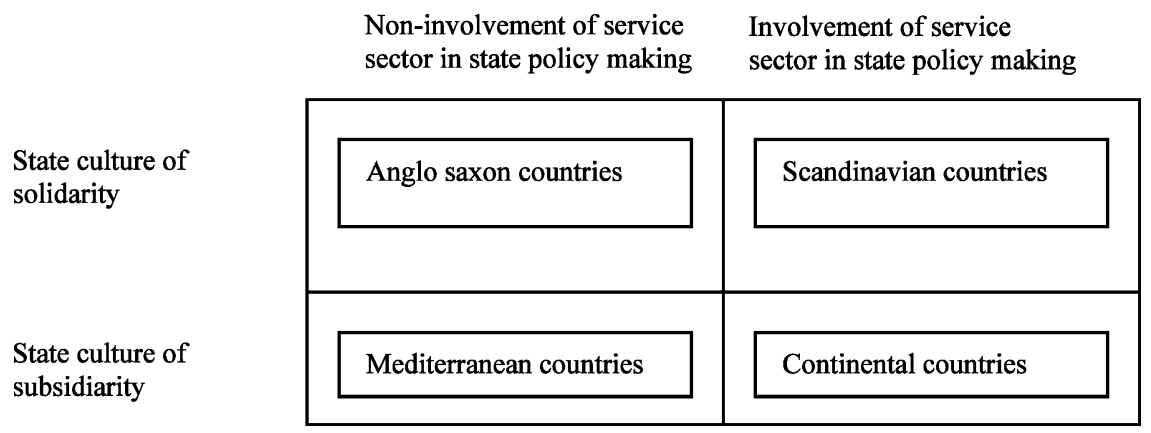

Fig. 1. The relationship between a public welfare culture and the service sector in the European welfare models. Source: Ascoli and Pavolini [1] 
resources earmarked by countries like Germany and Denmark; Greece invested 1/5 of the Community average, and Spain less than 1/2. Since then, harmonisation efforts have narrowed the gap. At the end of the 90s, the percentage of GDP going towards social protection costs for the different countries was: around 33\% for Sweden, Denmark and Finland, around 29\% for Belgium, Germany, France, Luxembourg and Holland; $22-$ $23 \%$ for Great Britain and Italy, $19.5-22.5 \%$ for Eire, Spain and Portugal, and lastly $16 \%$ in Greece ([14]).

Note that in two decades the relation between the countries investing least (Greece) and most (Scandinavia) goes from less than 1/10 to roughly $1 / 2$.

An interesting way of analysing the evolution of this parameter and relating it to the state role consists of calculating social 'protection as a percentage of GDP vs. the state contribution as a percentage of total social protection expenditure, as is shown in Fig. 2a and b ([11]).

In the time sequence shown by the two charts we can observe a gradual nearing of countries inside each of the 4 theoretic groups (in-group convergence), as well as progressive convergence of the 4 groups to each other (inter-group convergence). The average of all countries in social protection spending increased 7 points of GDP, while the average state contribution fell 3 points. This shows a general trend towards lesser state welfare finance at the same time as a better welfare provided society overall. From this we deduce that the fall in the state contribution has been offset by ever greater market participation and a growing assumption of responsibility by individuals for their own welfare.

The gradual convergence in welfare indicators is also a consequence of the identification of similar problems to be solved in all states. One of these problems, gradually attaining greater and greater importance, is the finance of welfare systems. It is precisely the finance efforts of the less developed countries which is making convergence possible, and the state investment effort is reflecting in tax levels. As KAUTO says [11], the main cause of convergence is increases in tax levels among the southern countries, though from 1980 till now the

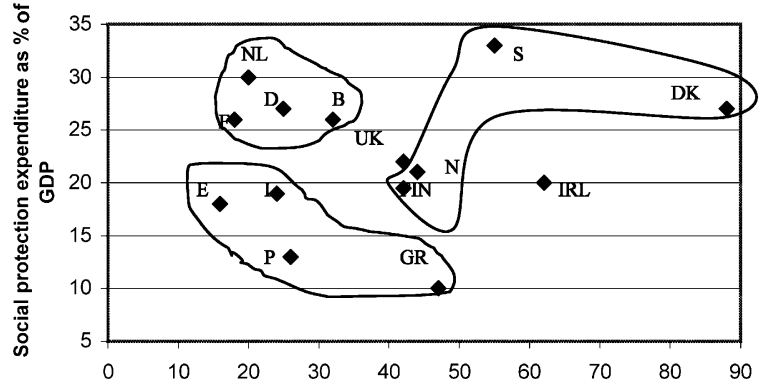

(a) General goverment contributions as \% of total protection financing

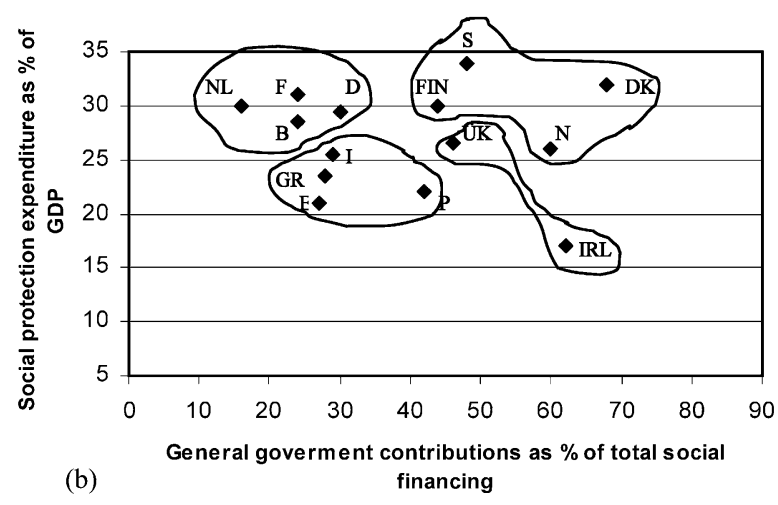

Fig. 2. Social protection expenditure (\%GDP) vs. government contribution ( $\%$ of total social protection spending). The situation in 1980 (a) and 1997 (b). (a) 1980-With the exception of the continental group (NL, F, D, B) which are close in this area, the other groups are quite dispersed: differences are big and it is not easy to mak out coherent group structures. However, the position by quadrants of at least 3 of the 4 groups is a differentiating feature. The average distances between countries of each group go from five for the continentals, up to 17.4 for the Nordic area, while the average distance between groups is 15.2. Sweden is the countries with greatest social spending, while the Danish government takes on the greater percentage of total expenditure of any country in 1980. (b) 1997-The countries have evolved and convergence can be seen inside each group and between groups. The distances between the groups have changed: the southern group went from 10.2 in 1980 to 5.6 in 1997, and the Nordic group fell from 17.3 in 1980 to 9.7 in 1997 . The southern states have essentially raised their social spending. In the other feature the extreme values in government finance closed with each other in the Mediterranean and Nordic groups. Convergence is more pronounced in the vertical than the horizontal axis. Source: Kautto, pp. 250-251 [11].

Scandinavian countries have also raised taxes significantly. Taxes, however, cannot be raised indefinitely. Ever since Bismarck's time, doubts over financial sustainability have always accom- 
panied welfare states, and questions such as employment and European population ageing have renewed this uncertainty over recent years.

In this scenario, whose horizon is still some decades away, this study concentrates precisely on the problem of the social sustainability of welfare, with special emphasis on the southern European states, studying the evolution of certain parameters which suggest that current policies are incapable of maintaining welfare levels. Finally, we propose an alternative model based on new axiological, legal, economic and social models, whose main consequences are briefly discussed.

The road, which countries must follow, to attain convergence will be different for each, as their starting point is also different, but the final state will necessarily be similar, as a consequence of mechanisms and flows countering inequality (for example, worker flows in a single market). Hence, in taking the case of Spain as our study subject, we are trying to exemplify one possible evolution path for the southern countries, and a possible final state of convergence for all European countries.

\section{Three threats to the mediterranean welfare system}

Data culled from diverse sources show various threats to the maintenance, quality and universality of southern European welfare. There are three core analysis areas we now wish to summarise, analyse and relate to each other: the consequences of an ageing population, the consequences of an increase in dependent persons, and the consequences of a crisis in the informal support provided by families.

These factors in turn are affected by and affect other variables, as in general the so-called welfare state has a notably systematic character: each variable affects and is affected by a series of other variables, and generally not in a linear fashion. From this complex perspective, welfare occurs in a scenario whose main actors are the state, the market and the family, whose acts focus on indirectly or directly providing care, services, support, finance and rights. In general, welfare is associated with aspects of education, health, social services, employment, collective services, housing and the law, and the differences between states depend on the greater or lesser importance granted the different social actors and aspects, prioritisation of one over another when earmarking funds, the scope of rights and the responsibility assumed or passed on by the state, the market, the family or the individual.

In Fig. 3 we show a simplification of the part of the welfare system to which our work refers. Note that the option of a strong state as the leading welfare agent presupposes the need for greater state revenues through taxes and duties, money with which to supply more social aid and better health services, greater unemployment assistance and stronger job creation investments. However, state expenditure in certain items like health could explode for reasons such as rising life expectancy and dependency. Bearing in mind that tax pressure is already high in these countries, a significant tax increase is not possible and financial problems appear.

At the same time, family-based societies like the Mediterranean provide much informal help, keeping the state expenditure contribution low. However, the more family-based a society, the lower the female employment rate, and families' acquisitive power is lower than in other countries so that high tax rates are not easily achieved, and neither can strong private sector investment be expected in welfare services in the market, which will hence remain small and dependent on state subsidies. As a consequence, the state can never achieve revenues comparable to other welfare systems and does not have substantial resources to devote to finance of free services such as health or education. The rising demand for long term care will pose a problem for the state (health services demand) and for families who have to take on care without help from the market).

Due to its systematic nature, the so-called welfare state is constantly evolving to serve the changing needs of the societies who adopt it. The inevitable result of a change in one structural parameter of the welfare state in a country is a fullscale modification in the whole of the rest of the system, causing the evolution of the system in each country. The will to unite Europe brings as a 


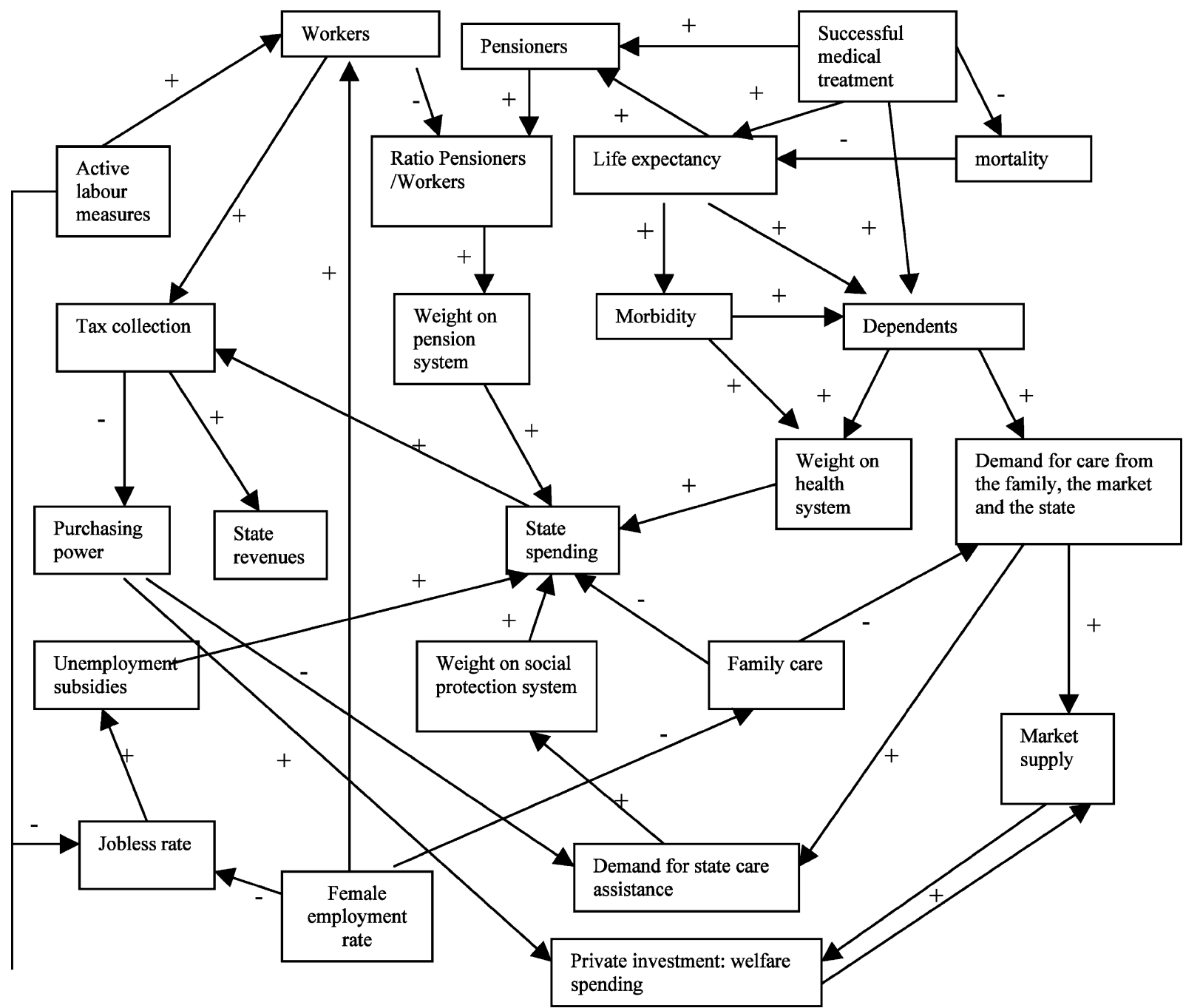

Fig. 3. Welfare as a system. Note: The sign ' + ' represents a direct relationship: an increase or decrease respectively represent a increase or decrease. '-' shows an inverse relationship: an increase/decrease here implies respectively a decrease or increase.

consequence a switch in pressure on welfare states from inside to outside the country, forcing us to initiate structural and working changes tending to bring countries into balance and eliminating their differences. The new state of stability in the welfare system should be similar in every European country: at medium term we are looking at a 'de facto' convergence of all the European welfare states, arising from the need to face very similar problems with viable solutions.

One of these problems is population ageing: the European Union is ageing rapidly, according to available data. In year 2000, among nations where the population aged 65 or more is higher than the European average of $16.2 \%$ we find countries like Italy (18\%), Sweden (17.3\%), and Greece (17.1\%) (Fig. 4a and b). The forecast for 2020 puts these percentages at $23.2 \%$ for Italy, $23.1 \%$ for Finland and $22.1 \%$ for Sweden.

Taking Spain as an example of a southern state, in 2001 there were 41116842 inhabitants and $16.9 \%$ of these were aged 65 or more. Forecasts for coming years also show continuous growth. Hence in year 2010 the elderly will represent 18\% 


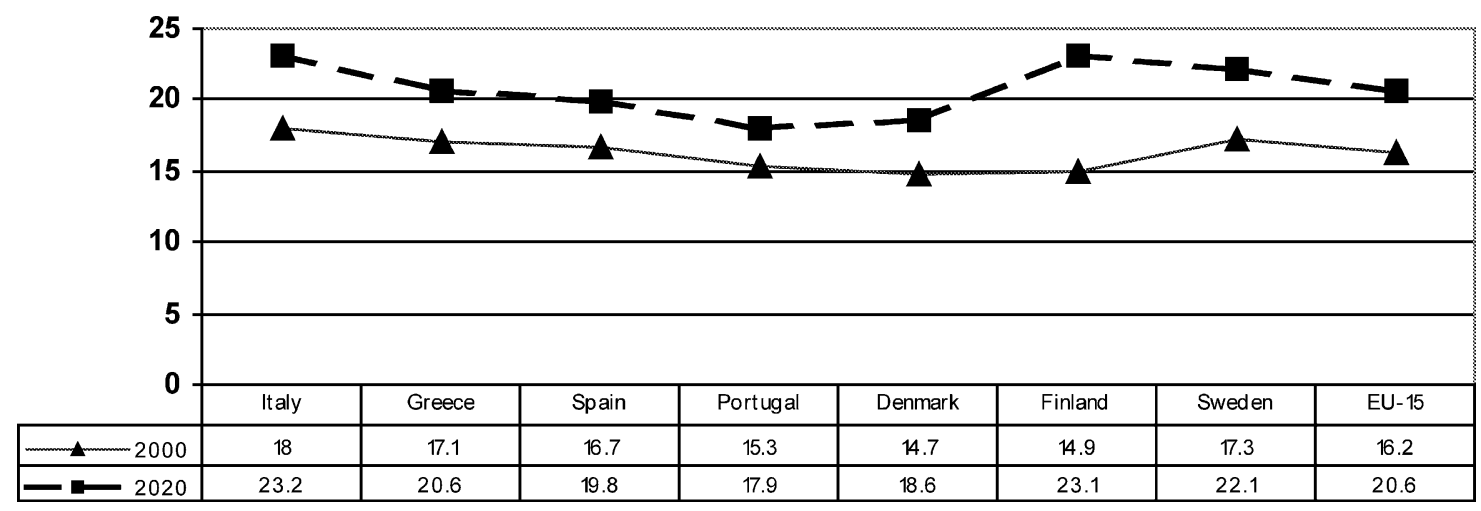

Fig. 4. Forecast growth of population aged 65 or more in the European Union, 2000-2020. Source: Eurostat (1999): Statistiques démographiques, 1995-1998, Luxembourg; quoted in [10]. (NB) Percentage of total population.

of the total population, $22 \%$ in 2025 and almost $30 \%$ in 2040. Estimates for the population aged 80 or more $(3.8 \%$ of the total population in 2001$)$ run at $5 \%$ in year 2010 and $8 \%$ in 2040 [13]. The rate of growth of the population aged 80 or more far exceeds that expected in the total over- 65 population. Hence over the period 2001-2026 29.5\% growth is expected in the over $65 \mathrm{~s}$ group, while the over 80 population will increase $58.7 \%$ (Spanish Population Projections of the CSIS demographic institute, stated in the Citizen Rights report, 1999 [5]).

The progressive ageing of the population means an increase in the rate of economic dependence (number of pensioners/ working population) implying a gradual rise in the economic pressure on pensions systems (Fig. 5), even taking into account the immigration process allowed by current policies. For example, over recent decades the total amount of pensions has increased by a factor of 4 in Spain. An ever smaller group of workers must maintain a greater number of pensioners through the taxes and social security collected by the state. With the current pensions system, the increase in the economic dependency rate implies a progressive increase in these contributions, and hence a decline in workers' disposable income, leading to a fall in their own welfare level. As neither taxes nor contributions can be hiked indefinitely, this rising dependence represents a direct threat to sustainability of present pensions systems.

Furthermore the support period for pensioners is ever longer, given the decline in the mortality

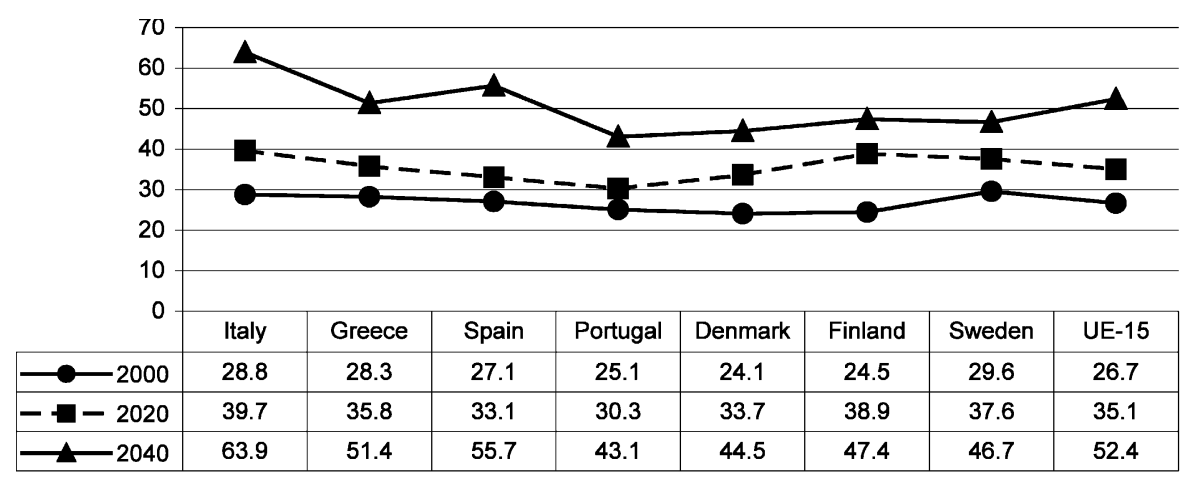

Fig. 5. Projections of economic dependence in the over-65 population in southern and Nordic EU countries. Proportion of persons aged over 65 in relation to the population of working age, as a percentage. Source: Eurostat, quoted by the European Economic Policy Committee in its report on the impact of ageing, 2000. 


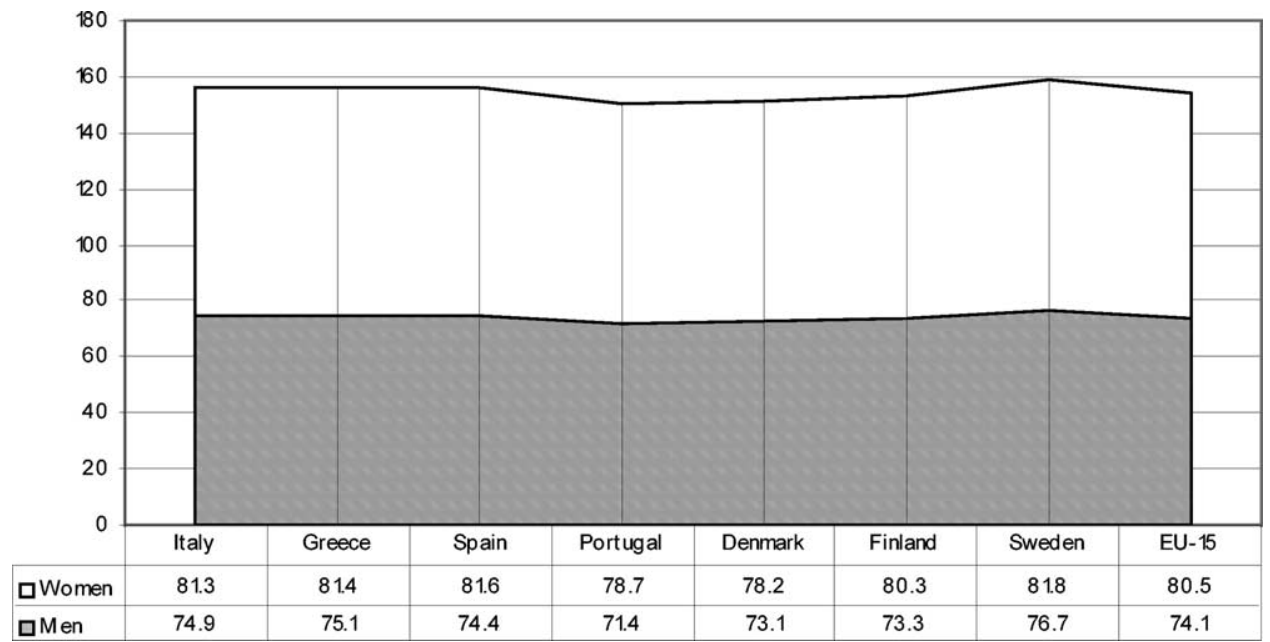

Fig. 6. Life expectancy at birth in European Union countries in 1997, by sex. Source: compiled with Labour and Social Affairs Ministry figures, 1999.

rate and the consequent increase in the population's life expectancy (Fig. 6).

However, falling mortality and longer average life expectancy have been accompanied by an increase in morbidity. This means there are ever greater numbers of sick people of an advanced age. Many illnesses that previously were terminal have become chronic sicknesses due to the advances in medical treatment. The result is that both among the elderly and younger people we observe a progressive increase in numbers of people needing long term care due to chronic illnesses which tend to end in complex, multiple complaint clinical states. The obvious consequence of all this is increased demand for social and health care, as reflected in Fig. 4.

In a welfare state this demand must be attended, and in fact this is the case in the majority of European countries. As health care is one of the pillars of welfare, it is considered a subjective and free right in the majority of developed nations. Thus, we can expect increased health expenses from the rise in morbidity associated to longer life expectancy.

If for example we look at per capita health spending in European states, we see a very notable increase in all countries over the last two decades (Fig. 7). Over the last 10 years per capita health spending in Spain and Portugal has risen over
$200 \%$, with an over $100 \%$ increase in Denmark and almost $150 \%$ growth in Norway ([12]). These figures reveal a clear message: the relative increase in health spending is shooting up in all countries, reaching extremely high levels, and there appears to be no ceiling other than that represented by the financial limits of the system: if per capita health expenditure continues to rise at present rates (over $100 \%$ every 10 years in all cases), in a very brief period of time the health system will involve expenses that the free health care services cannot bear, and a crisis will result associated with a rupture of the principles of universality and/or quality of life.

Finally, the Mediterranean states share one characteristic which in turn distinguishes them from the other European nation groups: their marked family-based nature. In these countries, the institution, which turns out to be the main source of welfare is traditionally the family. Specifically, the structure of the Mediterranean family allows this service provision thanks to women's presence in homes, acting as a cohesive element for three generations: their own, the previous generation (parents, parents in law) and the following one (their children). This traditional structure is reflected, among other indicators, in the female employment rate (Fig. 8). This indicator, as we said earlier, is one of the measures that 


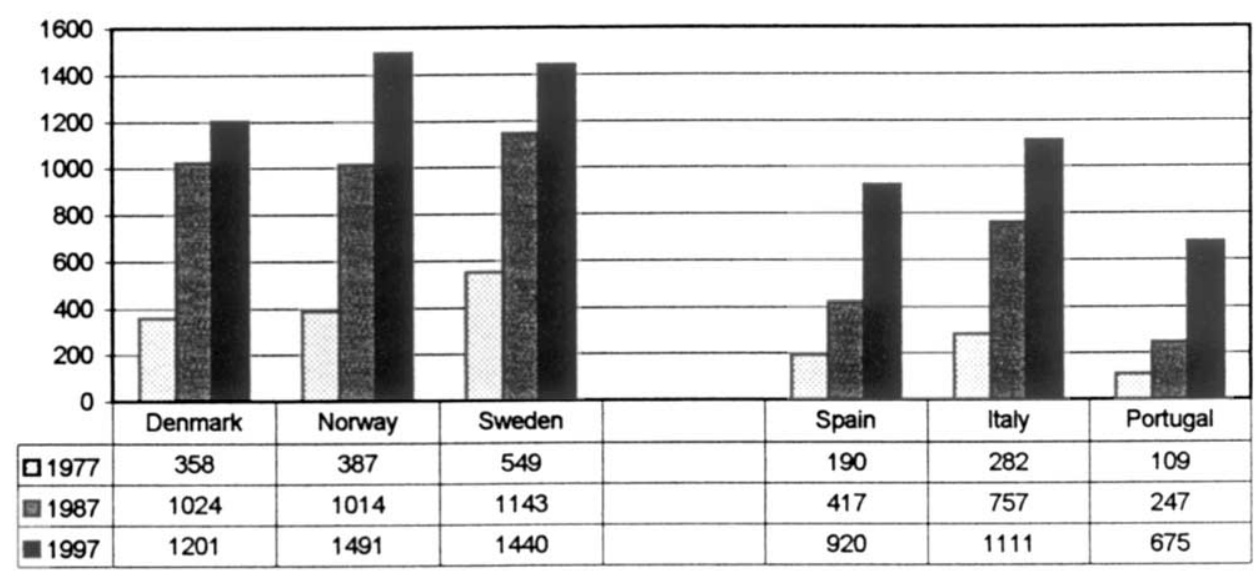

Fig. 7. Health spending per capita in \$ PPP (purchasing power parity) in Europe. Source: Eco-Health OECD1998.

currently shows significant differences among the four theoretic groups of European welfare states. The ratio of female to male workers is around $90 \%$ in Scandinavia, roughly $70 \%$ in countries like Holland and UK and $54 \%$ in Spain. Nonetheless, convergence is taking place in this field as well. According to [7] we are witnessing the social advance of defamilisation as a consequence of women's growing economic independence and the social pressure in favour of equal opportunities for the two sexes, among other reasons ([6]).

The family is the main welfare provider in the whole Mediterranean region, and its contribution is visible in many areas such as education, social training, protection, unemployment support, sickness and disability care and social and emotional support. As such, the indicators related to care provided by this institution are also organic indicators of the welfare system. According to studies by [7] relationship can be observed between state expenditure in services to families as a percentage of GDP and the female employment rate, very high in Scandinavia and still low in the southern countries. This implies that the unstoppable growth trend in female employment rates taking place fundamentally in Mediterranean countries, but also in central European and western nations, will be accompanied by a progressively stronger need for new services, whether to families or to the people that the families cease to care for. Evolution in the Mediterranean countries, till now characterised by a strong component of in-family welfare services provision ([6]), will follow the pattern of the Scandinavian, central European and British countries, multiplying by a factor of 5-10 times their state expenditure needs in family services, state nursery coverage or home help for the elderly, among other indicators.

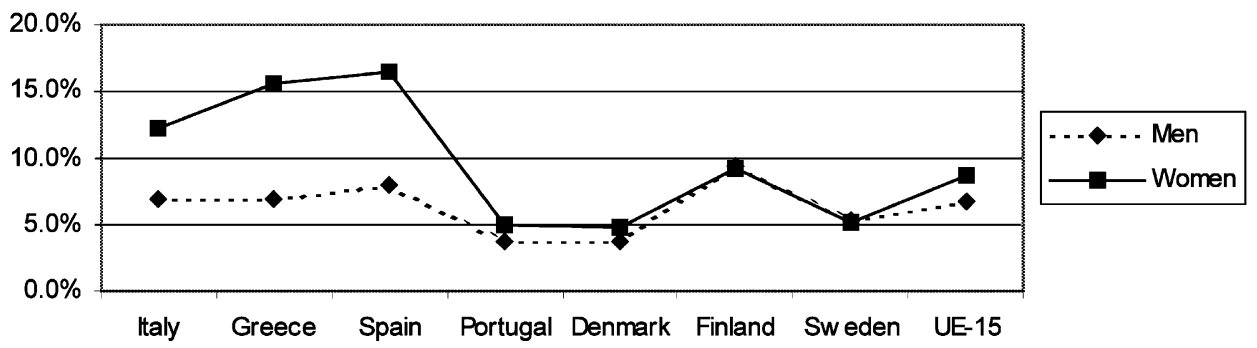

Fig. 8. Unemployment rates by sex (April 2002). Source: Eurostat, Euro-Indicators, no. 78/2002. Note: Figures for Greece refer to May 2001. 
In Spain, the availability of potential volunteer carers of dependents decreases as more and more women join the job market and the working population. In fact, the overall improvement in activity levels in Spain is mainly due to incorporation of the female population, the $34.8 \%$ female employment rate of 4th quarter 1993 rose to $40.7 \%$ by 4 th quarter 2001. However, unemployment among women is still high $(19.9 \%$, at 4 th quarter 2000 vs. $9.5 \%$ for men) and the shortfall to average European female employment rates still substantial (this average figure came out at $46.9 \%$ in 2000 , according to Eurostat data, though in countries like Denmark female employment is running at $60.2 \%$ ) Current female jobless rates are at a similar distance from average European rates $(8.9 \%$ for the EU-15). These figures show that women's incorporation in the Spanish job market is still at the development stage.

The high cost of private care services and the rapid pace of change in the family structure over the last 20 years, bringing a sharp decline in potential home carers, has not been accompanied by a large scale political agreement towards construction and consolidation of a welfare system which evolves in tune with the demand for services.

The majority of families seeking state help in the social services system come up against the 'scales wall' as the 1999 Citizen Defence report puts it [5]. The scales in place tend to fix extremely strict requirements to be able to access state services, but the requirements have nothing to do with the objective circumstance of needing help to carry out activities of daily life ${ }^{1}$, meaning that the ultimate destination for many applications is a waiting list. In this way, present social policies have undervalued families' socio-economic contribution to welfare, providing care and attention to dependents at no cost whatsoever to the state purse.

Hence the rise in demand for long term care services we dealt with above, and the crisis of informal support (families), means growing de-

\footnotetext{
1 These tend to penalise the existence of a relative who is taking on care of a dependent, and earning a certain (small) level of income is the usual motive for exclusion.
}

mand to the state for health care services implying an economic charge for the state (Fig. 4). To this situation we must add the ever greater expenditure in health services, whose budgets in the southern countries are around 10 times higher than the budget for social services.

We must remind you that in many states, health care is a subjective and free right; that is, a prescribed right, in contrast to social services, which must be requested and financed, at least in part, by the applicant. In this way, given a need for care, users prefer to opt for the health channel rather than the much less expensive (for the state) social channel. Hence the absence of a balanced legal system which contemplates social and health care needs as rights of the welfare state that cannot be waived, also leads to accelerated growth in health costs and a heavy extra charge for Social Security.

Thus the increase in state costs associated with welfare services in the southern welfare states has several sources:

- Population ageing with the consequent increase in the proportion of pensioners;

- The increase in life expectancy, lengthening the period of pension payments;

- The increase in demand for long term care for the chronically sick, often with pluri-pathological profiles of some clinical complexity;

- The exaggerated use of very expensive health services which are nonetheless free to users;

- The breakdown in family support due to women's incorporation in the job market, changes in the family structure and the high cost of private services, leading to a demand for care from the state and the market.

Upholding the welfare state in these countries very probably requires social policies that design and plan at medium and long term a supply of social and health care services involving the coresponsibility of society and the market. The new system must be capable of alleviating the care and financial overload of the health system, rationalising and optimising the system of social services, and offering a new portfolio of social and health care services based essentially on at-home and 
health centre resources. The viability of the new system would involve use of case management methodology, enabling integrated actions between both systems.

If we maintain that the family breakdown phenomenon in Mediterranean welfare states brings with it the consequence of a breakdown in intergenerational family support, and that in parallel, a finance problem is expected for the health and social security systems due to the increase in ageing, dependence and life expectancy, we will have to re-design models which from a axiological and organisational point of view face up to the foreseeable social and economic nonsustainability of the present system.

The historical, demographic, financial, social, legal and cultural peculiarities of the Mediterranean welfare states hamper their evolution towards real emergence of welfare states such as the Scandinavian kind, but there are possible alternatives combining state social and health care actions with maintenance of family support structures and outsourcing services through the market.

A health care system such as we propose must be based on new axiological, legal and financial principles making it sustainable, and allowing real changes in the culture of social protection in the southern states.

\section{Basis for a sustainable health care system}

The new system we envisage is carried out through a health care model based on three principles whose acceptance is key to solving the problems arising in the health care field and ensuring the sustainability of the social protection system in the European Mediterranean countries. The principles of the model are:

Social sustainability

Quality of life

Social co-responsibility

Below we briefly develop the justification for and interrelation of these three basic principles.

\subsection{Social sustainability}

Taking as an example the scientific, political and social debate arising over the environment, where for the first time the problems of scarcity of resources and the search for solutions through the concept of Sustainable Development were raised, we adopt the principle of Social sustainability ([8]). This we define as the extension of the welfare principle of Universality in time, in such a way that welfare is a right, not only for the citizens present (or present in the near future as occurs when we look at only the three generations which coexist), but also for all those people who succeed us in time forming the society of the future.

From the axiological point of view, the principle of social sustainability takes on the value of intergenerational solidarity (this value is included and extended beyond the relation grandparentsparents-children), and is legitimised ethically through a wider and deeper re-analysis of the fundamental social values of freedom and equality: (a) freedom and responsibility, insofar as our present freedom implies the responsibility of taking into account our successors in our actions or the conditions of life we nurture; (b) equality of rights and obligations, for as a consequence of our actions, no present or future citizen should have their freedom, their options or their decisiontaking capacity impaired.

In this respect even the Scandinavian countries, those with the greatest welfare tradition and most developed systems, show an break in this intergenerational solidarity, translating as an increase in youth poverty levels and a simultaneous decrease in elderly poverty (Fig. 9).

The inclusion of the time dimension in welfare has consequences for decision taking in the present: our current actions should aim towards favouring and guaranteeing that the rights available to our fellow citizens are also available for all the citizens who succeed us. Every society has the obligation to watch over the welfare of its present and future members. As a consequence, any action aimed at benefiting present citizens which represents a prejudice or loss of rights, or decline in the welfare level of future citizens should be considered immoral. 


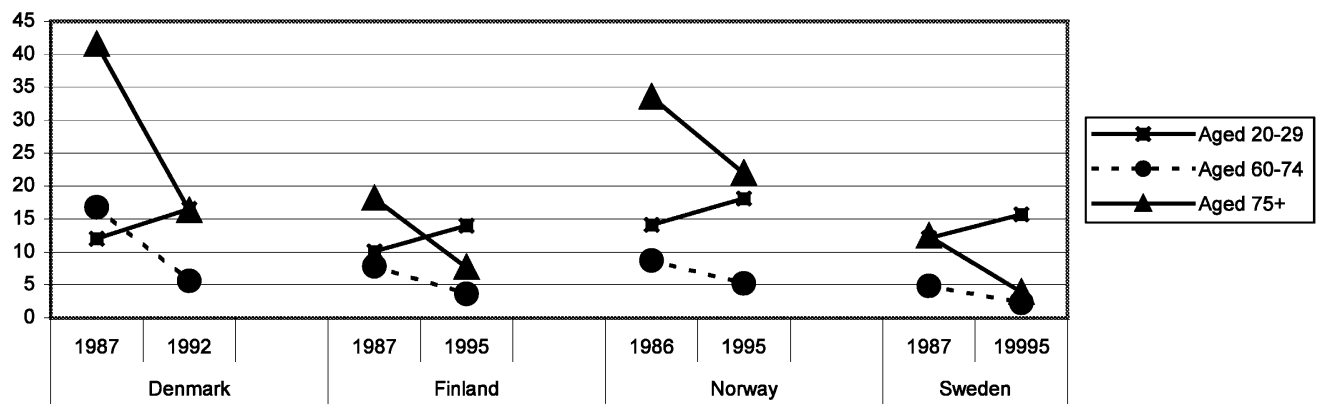

Fig. 9. Relative poverty rates by age in percentages. Source: Luxembourg income study, from Fritzell, p. 36 [11].

The Principle of Social Sustainability, in short, implies a conscious responsibility maintained over time towards our successors, and obliges us to include all future societies in the moral judgement of our actions. From this positioning, policies which either favour the few, or favour all now but prejudice others in the future, cannot be considered morally acceptable. Hence the two types of action present throughout the history of the welfare states cannot be accepted as satisfactory: (a) actions aimed at present welfare which involve a slow, but endless increase in state expenditure, because the tax charge resulting is greater for our successors and prejudices their chances of welfare. For example, if state health care is maintained subjective and universal while social care is considered objective and selective, health costs will increase indefinitely given the increased morbidity of the population; (b) Efforts aimed at creating welfare resources with cost that are used up and exhausted in a little time, because this means that they cannot be enjoyed by future society. One example would be creation of a special budget entry to raise pensioners' purchasing power without taking into account the imbalance between the working population and the population receiving the benefits.

In contrast, our efforts should go towards resources lasting in time whose practical bases should come from different sources:

\subsubsection{Legal}

Through new laws regulating the situations deriving from ageing. Till now, there are no specific laws in Mediterranean countries related to protection of dependents, a substantial omission, which does not reflect the importance of this problem according to demographic indicators. Neither are the tax rights and obligations clear for people who, owning property, request residential care from the state. The starting point should be development of a general rule regulating care to dependents as a subjective right which must be performed through the social and health systems. Spain as a Mediterranean country exemplifies the problems caused by a lack of the aforesaid regulation framework, as health care is structured regionally without legal recognition of dependency, provoking imbalances between regions, starting with the different definitions both of care profiles and the resources and services used.

\subsubsection{Care}

Families need help to continue their work as a source of welfare in the Mediterranean countries. If the aim is not to load the state with more care charges, and at the same time women's right to fulfil themselves as workers is recognised facilitating their insertion in the job market, the need arises to develop new resources harmonising both aims. One way of making this possible, from the point of view of maintaining family welfare, consists of converting volunteer carers into a legally recognised and remunerated work figure. In this way, the man or woman receiving economic and social incentives could consider continuing in the home as a carer. To this we would have to add the cost saving represented by not needing external assistance from the state. 


\subsubsection{Economic}

Sustainability should be based on co-responsibility and equity in finance of welfare services. Sustainable welfare needs new finance forms limiting the indefinite growth of some social costs. As we saw earlier, social and health care spending have increased constantly over the last two decades. We need to find new finance forms, which take pressure off the state system if we want to ensure its durability.

\subsubsection{Administrative}

New structures making decentralisation, integration and proximity of services possible, to bring them more into line with demand and more efficient.

\subsubsection{Cultural}

Cultural changes are necessary in the population in favour of social and financial co-responsibility together with the state social protection structures. No evolution of the Mediterranean welfare states will be achieved without a profound change in the way of conceiving welfare, not as a state handout, but rather as a right whose realisation depends on all citizens taking up responsibilities. In any event, the notable family-based nature of the Mediterranean countries, which represents an important factor in the subjective perception of welfare, can be preserved at the same time as directing attention towards social co-responsibility; towards the necessity of investing during one's working life to face up to a possible future state of dependency and care need.

\subsection{Quality of life}

The quality of life axiom in this model is not confined to establishing an objective and dignified standard of life, but should also be reinterpreted as a subjective citizen right. Quality of life in the social and health care model is achieved: on one hand, when a person manages to improve their subjective welfare remaining at home and with their family, as long as is possible, with a good degree of social and emotional support, following a therapeutic process of active rehabilitation directed both at the subject of treatment and their main carer; and on the other hand, optimising accessibility, which implies that the potential consumer obtains the service at the time and place and in the amount they need at a reasonable cost, eliminating physical, geographic, organisational, social and cultural barriers which hamper the efficacy and efficiency of resources.

This is to say that putting this principle into practice requires the following elements:

(a) Proximity, which can be defined as the lack of space between the person receiving the service and the person providing it. This means that in this health care model resources are used locally to create jobs linked to new need areas. The health care model must be able to offer dependent persons the services they require in nearby surroundings, starting from an interdisciplinary valuation of every situation. This involves design, launch and evaluation of an Integrated Plan for Personalised Care ([3,4,9]).

In reality, proximity is a quality of the model which is directly related to its efficacy and efficiency.

(b) The efficacy of the health care model is reached when users manage to improve their health and welfare remaining in their familiar surroundings, boosting resources such as athome help, phone assistance or medicines and home hospitalisation.

(c) Efficiency, or the relation between the real impact of the service and its production cost; suitability and cost are the factors informing efficiency. If the resource used is not ideal, the cost increases and effectiveness falls. Suitability is in turn linked to a totally integrated action methodology and resources availability, which implies extending the network of home, health centre and day care with the aim of reducing costs at the same time as raising user satisfaction.

\subsection{Social co-responsibility}

The welfare society enjoyed by a state that promotes social protection must, from the ethical point of view, be jointly responsible for the sustained maintenance of the state protection structures. Co-responsibility deals with the degree of individual or group involvement in the social 
and financial maintenance of public protection structures, when individuals enjoy an optimum quality of life enabling them to satisfy their needs for themselves. Individual responsibility for one's welfare and tax contribution to the state is interpreted here as a supportive, active contribution to finance of public welfare through part payment of services in the protection systems used, depending on income and the tax curriculum of the user and/or their relatives, so that other people who objectively cannot finance part of their needs also benefit.

For this reason it is possible and necessary to define, for example, how costs break down in the health and social system, with the purpose of making viable efficient and effective services consumption. Redefinition of the value of social justice requires the concurrence of social and tax factors: it is not fair or ethical that a person with economic and property assets gives away their goods to their heirs and then declares insolvency and applies for a place at a state residence; and it is not fair because if this is so then needs of other people in objectively more precarious circumstances cannot be attended and the only consequence over time is greater inequality among succeeding generations.

An increase in social and financial co-responsibility must constitute an activating element for private sector initiatives in welfare services, and help to financially alleviate the state system making it more sustainable. Taking on this principle does not mean a wager on individualism, responsibility and meritocracy worthy of the Friedmanian concept of welfare, which implies a residual state role. On the contrary, social co-responsibility means maintaining a state protection structure at the same time as individuals are made partly responsible for welfare.

Exploiting this system implies:

a) Encouraging capitalisation of pension funds, as Spain continues at the tail among European countries, to avoid the long term bankruptcy of the state system given the ageing population and rising life expectancy.

b) Promote dependency insurance laws in the southern countries, to alleviate families of part of the cost of long term care, avoiding or easing the breakdown of family support.

c) Defining the breakdown of costs for services, upholding citizen's right but individually financing the services depending on the objective tax situation of the person generating the cost.

d) Encourage market participation in investment in the health care sector, in such a way that the expense is shared by the state and the market.

Social sustainability, quality of life and social co-responsibility enable strategic planning of a European social policy capable of facing the forecast increase in demand for health care services.

\section{Conclusions}

In this study we have tried to show that: (a) social protection systems throughout Europe are converging; (b) we have common problems which threaten the welfare system's sustainability, such as ageing, dependence and the demise of the extended family; (c) viable responses are available through a health care system based on social sustainability, quality of life and social co-responsibility.

Summing up, European countries are currently in a convergence process which brings with it similar social, economic and political problems. In particular, welfare is beginning to be thought of as a supranational value requiring joint criteria and efforts in order to be maintained, given the problems occurring in all countries such as the rise in the proportion of pensioners and increased demand for long term care, both of which are closely linked to the population ageing occurring in Europe. Ageing represents an ever greater load on state health and pension systems. Furthermore, in the Mediterranean countries another factor obtains at the same time which directly affects the welfare supply; women's incorporation in the job market, which brings with it a gradually loosening of family ties in society. Given the breakdown of family support, which this ushers in, an increase appears in demand for state care, 
weighing even heavier on the public purse. These common problems are happening in contexts that are still different in their welfare state models, but convergence means positing responses, which are useful, in the long term, for all countries.

The consequence of the problems raised is a situation where the state cannot renounce its welfare coverage because this would violate the ethical principles on which the welfare state is based, such as solidarity, social justice and the dignity of the individual, but neither can this coverage be maintained because this would mean raising the tax cost to young workers to unsustainable limits for the benefit of the elderly, which goes against the values of intergenerational solidarity and social justice

The solutions to this situation require axiological, political, sociological and economic reflection questioning the bases assumed up to now without too much criticism: Should the state take on exclusive responsibility for welfare management? Is the family obliged to provide care for citizens without help? Is it fair that social and health coverage rights are the same for all citizens independently of their financial situation? Should the state take on alone the risks and long term care associated with dependence? Can these problems be resolved simply setting aside more state resources?

The response up to now all over Europe, has been, precisely, to increase state spending at the same time as introducing more and more selective evaluation measures for access to aid. This represents a step back on the road of universality towards growing selectivity and lower welfare accessibility for citizens.

Taking social sustainability, quality of life and social co-responsibility as the guiding principles for a new welfare system, we propose changes in the health care field aimed at answering the problems associated with the ageing of European society, the rise of dependence and southern defamilisation. Specifically, we propose:

a) View dependent persons rights and responsibility for their care through a new legal framework which includes laws for dependence. b) Unify social and health care in a single structure enabling services optimisation through individual health care programmes evaluated by case managers.

c) Promotion and development of at-home health care resources which are less costly than institutional expenses and increase user satisfaction and quality of life.

d) Encourage the family's participation as a welfare source through economic and in-kind remuneration and recognition of the working status of carers.

e) Promote individual savings for the financial risk associated with retirement through pension plan capitalisation. This risk stems from the lengthening of average pension payment periods and the imbalance between worker numbers and pension recipients, as well as the increased costs from growing morbidity.

f) Encourage measures towards dependence insurance creation capitalised over the working life, which cover part of the cost generated by long term care.

g) Change the welfare culture away from a conception of the state as the sole tutor of welfare and towards co-responsibility in welfare supply through taking out private sector services in a wider market.

In short, for true social sustainability in the European welfare systems exist for which future generations can benefit, it is necessary to plan a social policy taking in the diacronic and synchronic dimensions of welfare. If we aim to uphold quality of life as an essential subjective value we must create instruments to stimulate social and financial co-responsibility which represent a supportive and active contribution of satisfied society to unsatisfied society.

\section{Acknowledgements}

Ministry of Science and Technology of Spain, Project SEC 2002-02634. 


\section{References}

[1] Ascoli UY, Pavolini E, Las organizaciones del tercer sector en las políticas socio-asistenciales en Europa: comparación de diferentes realidades', en Muñoz, Garcia y Gonzalez (dirs.): Las estructuras del bienestar en Europa, Escuela Libre Editorial-Civitas, Madrid, 2000; pp. 827-858.

[2] Barea. Gastos de protección social, política de convergencia y competitividad. Papeles de Economía Española 1991;11:48.

[3] Challis D, Programas alternativos en las prestaciones a la tercera edad: prestaciones domiciliarias y gestión individualizada por casos', en Moreno L, (comp.) Intercambio socia y desarrollo del bienestar, Consejo Superior de Investigaciones Científicas, Madrid, 1993.

[4] Davies B. Care management, equity and efficiency The international experience. Canterbury: University of Kent, 1992.

[5] Defensor Del Pueblo, Sociedad Española DE Geriatría y Gerontología y Asociación Multidisciplinaria DE Gerontología, La atención sociosanitaria en España: perspectiva gerontológica y otros aspectos conexos Madrid, 1999.
[6] Esping-Andersen G. Social Foundations of Postindustrial Economies, 1999, Oxford University Press, Oxford.

[7] Esping-Andersen G. Estados de Bienestar y familias, en Muñoz, Garcia y Gonzalez (dirs.): Las estructuras del bienestar en Europa, Escuela Libre Editorial-Civitas, Madrid, 2000, pp. 731-744.

[8] Garcés J, La nueva sostenibilidad social. Ariel, Barcelona, 2000.

[9] Hébert R, 'Integrated Service Delivery For Frail Elderly People. The Canadian Experience'. Valencia Forum Spain, April 1-4, 2002.

[10] Imserso, Las personas mayores en España: Informe 2000. Ministerio de Trabajo y Asuntos Sociales, Madrid, 2001.

[11] Kautto M, Fritzell J, Hvinden B, Kvist J, Uusitalo H. Nordic Welfare States In The European Context, Routledge, London, 2001; pp. 232-261.

[12] López GY, Ortún V, Economía y sanidad. Fundamentos y políticas, Encuentro, Madrid, 1998.

[13] Ministerio De Trabajo y Asuntos Sociales, Guía de Ayudas Sociales para las Familias, Madrid, 2001.

[14] Montoro R, Los fundamentos teóricos de la Política Social', en C Alemán y, J Garcés (coords.): Política Social, MacGraw-Hill, Madrid, 1997; pp. 33-50. 